\title{
ARTIGO
}

do https://doi.org/10.22481/praxisedu.v15i35.5693

\section{“OS COMENTÁRIOS É QUE VALERAM A PENA”: PRÁTICAS DE LETRAMENTO E HETERONORMATIVIDADE EM REDE SOCIAL}

\author{
"THE COMMENTS THAT WERE VALID": LITERACY PRACTICES AND \\ HETERONORMATIVITY IN SOCIAL NETWORK
}

\section{"LOS COMENTARIOS FUE PAGABLES": LETRAS DE REDES SOCIALES Y PRÁCTICAS DE HETERONORMATIVIDAD}

\author{
Alexandre José Cadilhe \\ Universidade Federal de Juiz de Fora - Brasil \\ Roney Polato de Castro \\ Universidade Federal de Juiz de Fora - Brasil
}

\begin{abstract}
Resumo: Temos como objetivo construir uma compreensão sobre como práticas de letramento constituem-se de modo potente para produção de posicionamentos sobre o mundo social, a partir de análise de comentários publicados em uma rede social. Considerando-se a situacionalidade do evento de letramento em voga - os comentários de uma revista de educação tematizando questões de gênero e sexualidade - temos ainda o propósito de analisar como a heteronormatividade é justificada ou mantida como um enquadre epistêmico nos posicionamentos dos enunciadores dos comentários. Como resultados, apontamos que os comentários tomam como base mais a leitura de comentários anteriores do que o artefato publicado em si, bem como a religiosidade apresenta-se como uma episteme evocada para justificar posicionamentos conservadores que negam outras formas de viver o mundo social que não na ordem heteronormativa. Concluímos com alguns desafios que são postos ao campo da educação e dos estudos da linguagem.
\end{abstract}

Palavras chave: Letramento; Rede Social; Heteronormatividade; Educação

\begin{abstract}
We aim to build an understanding of how literacy practices are potent for producing positionings on the social world, based on the analysis of comments published in a social network. Considering the situationality of the literacy event in vogue - the comments of an education journal thematizing issues of gender and sexuality - we also intend to analyze how heteronormativity is justified or maintained as an epistemic frame in the positioning of the enunciators of the comments. As a result, we point out that the comments are based more on the reading of previous comments than the artifact published in itself, and religiosity presents itself as an episteme evoked to justify conservative positions that deny other forms of living the social world that do not in the heteronormative order. We conclude with some challenges that are put in the field of education and language studies.
\end{abstract}

Keywords: Literacy; Social network; Heteronormativity; Education 
Resumen: Tenemos como objetivo construir una comprensión sobre cómo prácticas de letramento se constituyen de modo potente para la producción de posicionamientos sobre el mundo social, a partir del análisis de comentarios publicados en una red social. En cuanto a la situacionalidad del evento de letramento en boga - los comentarios de una revista de educación tematizando cuestiones de género y sexualidad - todavía tenemos el propósito de analizar cómo la heteronormatividad es justificada o mantenida como un encuadre epistémico en los posicionamientos de los enunciadores de los comentarios. Como resultados, apuntamos que los comentarios toman como base más la lectura de comentarios anteriores que el artefacto publicado en sí, así como la religiosidad se presenta como una episteme evocada para justificar posicionamientos conservadores que niegan otras formas de vivir el mundo social que no en el orden heteronormativo. Concluimos con algunos desafíos que se plantean al campo de la educación y de los estudios del lenguaje.

Palabras clave: Letramento; Red social; Heteronormatividad; Educación

\section{Introdução}

Parece claro que estamos diante de um novo modo de aprender, de construir conhecimento, de atuar nas práticas de letramentos, e de estar no mundo social, que são muito diferentes das ações das quais os alunos participam em muitas escolas (MOITA LOPES, 2012, p. 207).

Fevereiro de 2015 foi o mês que o Brasil celebrou as irreverentes festas carnavalescas, onde subvertem-se normativas sociais a respeito de performances do corpo, do gênero, da sexualidade. Foi também o momento aleatoriamente selecionado para que uma revista tradicionalmente voltada ao campo da educação e da vulgarização científica para professores e professoras lançasse uma reportagem de capa um pouco peculiar. A capa em questão trazia a foto de uma criança britânica que, assim como boa parte dos brasileiros e brasileiras no mês do carnaval, também subvertia uma norma: era um menino que fazia uso de um vestido de princesa.

O menino em questão, Romeo Clarck, era então uma criança de oito anos que, por gostar de usar vestidos, foi impedido de entrar na escola. O que seria uma opção pessoal passa a ter implicações políticas: afinal, poderia a escola excluir uma criança por fazer uso de uma roupa que outra criança (menina) poderia usar? De todo modo, a questãoassumida pela Revista Nova Escola foi o convite à reflexão explicitada em sua capa: "vamos falar sobre ele?".

A revista tem com público-alvo professores e professoras da educação básica. Com uma tradição de mais de 30 anos em edições impressas, a publicação está inserida na ordem social contemporânea: seus textos são também divulgados em ambientes virtuais. Contudo, não se trata somente de uma permissão de acesso ao conteúdo, como marcado pela Web 1.0, 
mas sim a possibilidade de interação com seus interlocutores, a geração Web 2.0, em que emergem práticas de escrita colaborativa (MOITA LOPES, 2012). Se antes a editora da revista a disponibilizava por um site institucional, hoje esta é acompanhada por um perfil em rede social, tal como o Facebook. A revista, que antes era produto a ser consumido pelos profissionais da educação, passa a ser objeto de múltiplos letramentos em interações em rede: ela é lida, elogiada, criticada, compartilhada, curtida, etc., de modo a explicitar significados, leituras, interpretações socialmente compartilhadas pelos usuários de redes sociais, propensos leitores da revista.

Foi o que ocorreu em fevereiro de 2015: o perfil da revista em rede social, ao divulgar a capa de sua edição, teve um acesso multiplicado em mais de 30, comparando com o acesso nos meses anteriores. Só em 2015, a postagem ultrapassava mais de três milhões de visualizações, e mais de 400 comentários, além de mais de três mil compartilhamentos. Podemos levantar uma série de hipóteses sobre tal repercussão: a foto do menino de vestido na capa, o tema gênero e sexualidade na escola e suas implicações com as políticas públicas vigentes (ou em disputas) no país, as demandas das professoras e professores que leem a revista, etc. O editor-chefe da Nova Escola, Rodrigo Ratier, em entrevista ${ }^{1}$, apresenta uma outra leitura sobre o número de visualizações e os impactos da postagem da capa:

Eu diria, com base nos comentários no site e nas redes sociais, que há uma polarização, com um pendor para elogios à reportagem. No início da divulgação, os defensores foram ampla maioria, mas essa margem se estreitou, paradoxalmente, quando o Jean Wyllys divulgou o post no perfil dele no Face (ele nos avisou de que isso ocorreria, pois ele é seguido por muitos haters).

Assim, a capa da revista tornou-se objeto de leitura e crítica por um público que extrapola os/as interlocutores/as - docentes da educação básica. Sua repercussão aumentou por ser compartilhada por um famoso deputado federal já em segundo mandato (desde 2010), o Jean Willys, reconhecido por sua bandeira em defesa aos direitos humanos da população LGBTTI $^{2}$. Contudo, o referido deputado, ao compartilhar um artefato cultural, divulga-o não somente entre seus/suas apoiadores/as, mas sobretudo entre aqueles/as que discordam de seu posicionamento e o atacam discursivamente nas redes sociais - os chamados haters.

\footnotetext{
${ }^{1}$ Entrevista concedida ao site Lado Bi: cultura e cidadania LGBT na real e com local, disponível em http://ladobi.uol.com.br/2015/02/nova-escola-identidade-genero/

${ }^{2}$ Referência a Gays, Lésbicas, Bissexuais e pessoas trans (travestis, transexuais, transgêneras) intersex, além de outras identidades políticas reivindicadas por diferentes grupos. O referido deputado, após inúmeras ameaças de morte, foi levado a abrir mão de seu mandato em 2019.
} 
Este breve relato do editor também explicita uma série de práticas de letramentos (cf. LEMKE, 2010; ROJO, 2014; BARTON; LEE, 2015) vigentes no mundo contemporâneo: textos podem ser acessados em larga escala; os significados são socialmente compartilhados; as comunidades interpretativas são múltiplas; as trajetórias de entextualização ${ }^{3}$ em rede potencializam os significados; as práticas de leitura são marcadamente políticas e possibilitam a produção de diferentes identidades sociais, sobretudo nas temáticas de gênero e sexualidade. São sobre estes temas que nos debruçamos neste artigo, trazendo ainda implicações para reflexões sobre o campo da educação, a formação de leitores e leitoras críticos/as e o papel de uma escola cidadã no respeito à diversidade.

Assim, temos como objetivo construir uma compreensão sobre como práticas de letramento constituem-se de modo potente para produção de posicionamentos sobre o mundo social, a partir de análise de comentários publicados em uma rede social. Considerando-se a situacionalidade do evento de letramento em voga - os comentários de uma revista de educação tematizando questões de gênero e sexualidade - temos ainda o propósito de analisar como a heteronormatividade é justificada ou mantida como um enquadre epistêmico nos posicionamentos dos enunciadores dos comentários. Deste modo, trata-se de um estudo qualitativo sobre práticas sociais desempenhadas na Internet (LANKSHEAR; LEANDER; KNOBEL, 2015), cujos dados gerado são analisados a partir da Análise do Discurso pelo viés da Linguística Antropológica (WORTHAM; REYES, 2015), considerando, sobretudo, o conceito de posicionamento tal como aplicado por Barton \& Lee (2015) para análise de interações em espaços digitais, conforme será explicitado nas próximas seções.

Para isso, organizamos este texto em mais quatro seções: na primeira, discutimos uma concepção de letramentos como práticas sociais situadas, bem como os letramentos que emergem de interações em redes sociais; na segunda, abordamos o caso da Revista Nova Escola, ao tratar a temática de gênero e sexualidade; na terceira, analisamos e discutimos os posicionamentos dos leitores e leitoras da capa da revista a partir da análise do discurso de comentários em redes sociais; por fim, apresentamos nossas considerações provisórias sobre as implicações para a educação.

\footnotetext{
${ }^{3}$ Podemos entender entextualização como o "processo de tornar um discurso extraível, de transformar um trecho de uma produção linguística em uma unidade - um texto - que pode ser retirado de seu cenário interacional" (BAUMAN \& BRIGS, 1990 apud FABRICIO, 2014, p.151).
} 


\section{Letramentos, redes sociais e produção de posicionamentos}

Ao mencionarmos a situação instaurada a partir da publicação da capa da Revista Nova Escola na página do Facebook ${ }^{4}$ da revista, bem como os efeitos desta nas interações possíveis nesta rede, compreendemos que tais ações constituem diferentes práticas de letramento, situadas "num mundo social textualmente mediado, onde os textos são partes da cola da vida social" (BARTON; LEE, 2015, p.44). Ainda segundo David Barton e Carmen Lee,

[...] textos são centrais na interação social, e grande parte da linguagem falada é executada no contexto da linguagem escrita e a leva muito em conta. Linguagem e letramento estão no cerne de grande parte da mudança social atual, porque são a linguagem e o letramento que estruturam o conhecimento e possibilitam a comunicação (Idem).

Em outros termos, significa pensar que eventos de letramento são constituídos por interações sociais entre sujeitos, e tal interação é marcada pela presença de um texto.

Letramentos, neste contexto, são compreendidos como "um conjunto de práticas sociais interdependentes que interligam pessoas, objetos midiáticos e estratégias de construção de significado" (LEMKE, 2010, p.455). Contemporaneamente, tais práticas são duplamente marcadas: por um lado, temos a diversidade cultural que a cada dia encontra-se mais hibridizada, evocando a urgência de uma conscientização ética e cidadã nas práticas de uso da linguagem; por outro lado, a circulação dos discursos são também acentuadas por uma série de recursos semióticos. Se antes a linguagem verbal escrita imperava nos textos, hoje temos gêneros discursivos que mesclam a linguagem oral, a imagem, o som, o movimento, os diferentes layouts e configurações como recursos que também produzem significados. Assim, no lugar de letramentos, podemos fazer uso do conceito de multiletramentos (cf. ROJO, 2012; BARTON; LEE, 2015).

Um exemplo de práticas multiletradas pode ser ilustrado justamente com o que acontece na interação em sites de redes sociais: ao termos acesso a uma página virtual de um jornal, podemos clicar em sua manchete, ler, produzir comentários (fazendo uso do texto verbal escrito, mas também memes, emoticons, imagens em movimento, links para outros textos, etc.), curtir (atualmente disponibilizada com símbolos que também expressam a

\footnotetext{
${ }^{4}$ Uma das redes sociais virtuais mais acessadas no mundo, com mais de 2 bilhões de usuários no mundo, o Facebook "foi criado em 2004, por quatro alunos da Universidade de Harvard: Mark Zuckerberg, Dustin Moskovitz, Chris Hughes e o brasileiro Eduardo Saverin. O objetivo inicial era reunir alunos da Universidade de Harvard, mas seu sucesso ultrapassou os muros daquela universidade e chegou a outras. A partir de 2006, quando abriu acesso a qualquer pessoa com mais de 13 anos com um e-mail válido, a nova rede social alcançou o mundo" (PAIVA, 2016, p.66).
} 
opinião do leitor), compartilhar com comentários também multimodais, etc. Todas estas práticas configuram diferentes ações por meio da linguagem em contexto virtual (BARTON; LEE, 2015; PAIVA, 2016).

Essas práticas são também marcadas pelo que Luiz Paulo da Moita Lopes (2012) chamou de "novo ethos" dos letramentos em contextos digitais: "além de incorporar novos sentidos para o que conta como letramento, incorpora também novos significados sobre quem somos ou podemos ser" (p.205). Em outras palavras, entra em jogo o potencial de produção de diferentes identidades sociais quando interagimos nestes contextos. Identidade é aqui compreendida não como um produto ou um fato, um elemento fixo, mas como uma performance, uma ação, um ato, um corolário de práticas colocadas em jogo e socialmente situadas (NELSON, 2006; MOITA LOPES, 2012; BUTLER [1990]2013).

Válido ressaltar que, como toda ação discursiva, tais práticas não são neutras. Elas são marcadas por índices que podem nos informar diferentes posicionamento sociais e identitários diante do tema em discussão. Barton e Lee (2015) atualizam, neste contexto, o conceito de postura/posicionamento para construir uma compreensão sobre os modos de participação em redes sociais. Os autores citam dois tipos de posicionamentos comuns em interação virtual: a "postura afetiva, que sinaliza sentimentos do falante" (BARTON; LEE, 2015, p.118), e a "postura epistêmica, que sinaliza seu conhecimento e crença em relação à declaração" (idem). Estas, claro, não são excludentes, e podem ser produzidas de forma híbrida nos diferentes modos de participação social por meio do discurso.

Consideramos, para fins de reflexão neste artigo, a interação ocorrida a partir de uma postagem no Facebook, como indicado na Introdução, enquanto um evento multiletrado constituído por diferentes práticas. Levaremos em conta a prática de produzir comentários a partir da leitura da capa da revista. Antes, contudo, apresentamos algumas considerações sobre a capa da revista em si e o tema que ela evoca.

\section{Gênero, sexualidade e educação em capa de revista circulando em rede social}

O convite apresentado pela Revista Nova Escola - Vamos falar sobre ele? - não é uma proposta nova. Há uma trajetória de estudos e pesquisas que buscam articular o campo da educação aos estudos sobre relações de gênero e sexualidades, que atravessam outros campos de conhecimento. Talvez seja relevante pensar que esse convite retoma a proposta dessa articulação: é possível pensar gênero e sexualidade como aspectos educativos? De que modo? 
Sob uma perspectiva social, tomamos gênero e sexualidade como campos discursivos, sempre em disputa, produtores de sentidos sobre a vida social. Com isso apontamos para essas categorias como importantes elementos para problematizar os modos pelos quais nos constituímos e como nos relacionamos com os outros e com as instituições sociais. Assim, cabe pensar gênero e sexualidade como integrantes de processos educativos, como elementos de redes pedagógicas que contribuem para que nos tornemos o que somos, organizando a vida social, instituindo os lugares e as possibilidades de existência de cada sujeito.

Com essa perspectiva destacamos, em primeiro lugar, que não se produz educação apenas nos locais social e culturalmente instituídos para esse fim, ou seja, há relações pedagógicas nas instituições como escola, família e igreja, mas isso se estende para os meios de comunicação e mídias digitais e para os variados artefatos e rituais culturais, sempre que isso envolver produção de saberes, exercício do poder e constituição de sujeitos (SABAT, 2001).

Segundo, pensando especificamente na educação escolar, os estudos de gênero e sexualidade vêm apostando na problematização da escola como instância de produção de subjetividades a partir de regulações que normalizam os sujeitos, ou seja, o investimento na produção de homens e mulheres saudáveis e "normais", ajustados/as aos valores e às moralidades sociais. Em outros termos, problematiza-se a educação heteronormativa, compreendendo heternormatividade como a ordem social do presente, na qual todo mundo é criado para ser heterossexual, ou - mesmo que não venha a se relacionar com pessoas do sexo oposto - para que adote esse modelo de heterossexualidade em sua vida (MISKOLCI, 2013, p.15).

A educação escolar participa ativamente da produção e reiteração dessa heteronormatividade. No espaço escolar são instituídas e exercidas técnicas de disciplinarização, vigilância e punição, naturalizadas como educativas. Na escola se ensina que ser dissidente das normas de gênero e sexualidade significa estar submetido/a a sanções que envolvem preconceitos, discriminações e violências:

Currículos, normas, procedimentos de ensino, teorias, linguagens, materiais didáticos, processos de avaliação são, seguramente, loci das diferenças de gênero, sexualidade, etnia, classe - são constituídos por essas distinções e, ao mesmo tempo, seus produtores. (LOURO, 2011, p. 68).

O convite da Revista Nova Escola se coloca a partir de um desses casos em que as sanções heteronormativa se impõem aos sujeitos. A reportagem nos informa que o menino da capa, Romeo Clarke, adora usar seus mais de cem vestidos em atividades cotidianas, 
incluindo a escola. Por esse motivo, foi impedido de participar das atividades no contra turno escolar, até que se vestisse de acordo com o "seu" gênero.

Como Romeo, crianças e jovens enfrentam, cotidianamente, constrangimentos, violências e exclusões como parte do que seria a produção de sujeitos de gênero e sexualidade normais e ajustados aos parâmetros valorativos de uma sociedade e de uma cultura. Interessanos, portanto, ao nos vincularmos a esse campo de estudos e pesquisas em gênero, sexualidade, educação e linguagem, problematizar os currículos escolares como produtores de subjetividades, instituindo hierarquias e colocando em circulação técnicas sutis e naturalizadas de enquadramento e controle das fronteiras de gênero e sexualidade.

Por outro lado, interessa-nos pensar nas potencialidades do espaço escolar como lugar de análise e questionamento das regulações de gênero e sexualidade, da heteronormatividade, com vistas a contribuir para a produção de relações pedagógicas menos violentas e excludentes. Entendemos, ainda, as práticas de letramentos críticos como estratégia para questionamentos dessas regulações: a formação cidadã e ética é fortemente atravessada pelo modo como sujeitos participam de práticas de leitura e escrita no mundo social (ROJO, 2012; MOITA LOPES, 2012; BARTON; LEE, 2015)

Válido ressaltar que a preocupação com estes temas não é tão recente: tomemos como marco para pensar a produção no campo dos estudos de gênero, sexualidade e educação a história do grupo de trabalho (GT) 23 da Associação Nacional de Pós-Graduação e Pesquisa em Educação (ANPED). Como nos indicam Cláudia Ribeiro e Constantina Xavier (2014), a trajetória desses estudos é marcada por uma diversidade de temas, enfoques, metodologias de investigação e perspectivas teórico-metodológicas. Analisando 172 trabalhos apresentados em dez anos do GT, as autoras nos mostram que esse é um campo fértil, que toma para si a problematização de uma série de elementos educativos - currículos, materiais didáticos, artefatos culturais (filmes, revistas, músicas, publicidade, etc.), processos formativos, docências, políticas educacionais, educação em espaços escolares e não-escolares, em diferentes segmentos da escolarização (da educação infantil à educação de jovens e adultos), infâncias e juventudes, construção das masculinidades, feminilidades, homossexualidades e transexualidades, violências sexuais, homofobia e outras formas de preconceitos, discriminações e violências no espaço escolar, enfim, uma produtividade que nos remete a necessidade de pensar a escola e seu papel na produção ativa das relações de gênero e sexualidades. 
Consideramos relevante destacar outro tipo de investimento sobre a educação escolar no que tange às questões de gênero e sexualidade. Tem se produzido um conjunto de reivindicações nas últimas décadas, advindas de movimentos sociais feministas e LGBTTI, que têm como alvo a escola. Reivindica-se que as escolas abordem entre seus conteúdos as experiências dos diversos grupos culturais e sujeitos de gênero e sexualidade, como modo de ampliar a visibilidade e discutir a construção e manutenção de representações estereotipadas que são base para os jogos de poder que classificam, hierarquizam e subordinam esses sujeitos e grupos. É inegável a atuação dos movimentos feministas e LGBTTI na proposição de políticas que incluam as experiências de mulheres, gays, lésbicas, bissexuais, pessoas trans ${ }^{5}$ e tantas outras identidades e expressões de gênero e sexualidade nos materiais didáticos, nos conteúdos das disciplinas escolares, nos cursos de formação docente, nos documentos curriculares e legislações educacionais.

A reportagem de capa da Revista Nova Escola nos apresenta Romeo, Iana, Roberta e Emilson, que enfrentaram, de distintos modos, constrangimentos, exclusões, discriminações e violências que vem sendo objeto de estudo de pesquisas em educação. O convite da revista, nesse sentido, é também um alerta para pensarmos o alcance dessas pesquisas, ou seja, na relação entre as instituições de ensino superior e as escolas de educação básica existem hiatos, desencontros, que dificultam a ressonância dos conhecimentos produzidos no campo de gênero, sexualidade e educação para as práticas pedagógicas escolares. Com essa trajetória intensa e efervescente de estudos, que impactos se produzem na educação escolar? Tomando especificamente o espaço da revista Nova Escola no Facebook, que posicionamentos são marcados nas diferentes participações de sujeitos em site de rede social? Estariam os leitores e leitoras sensibilizados/as para essa discussão?

\section{Práticas de letramento em rede: posicionamentos heteronormativos em jogo}

A fim de ilustrar como diferentes posicionamentos são colocadas em jogo em situação de interação social em ambiente virtual, enquanto um evento de letramento, fizemos a seleção de alguns comentários que foram publicados em resposta a imagem da capa da revista. Estas postagens ocorreram ainda em 2015, quando houve a publicação da revista e, consequentemente, da capa, na página do Facebook da Revista Nova Escola. O convite a falar

\footnotetext{
5 A designação "pessoas trans*" foi utilizada para nos referirmos a sujeitos que expressam uma inconformidade com os enquadramentos impostos desde o nascimento sobre seus corpos. Algumas das denominações identitárias mais comuns para esse grupo incluem travestis, transexuais e transgêneros. Não temos a intenção de discutir essas categorias.
} 
sobre Romeo, estampado na referida capa, ganha outros contornos quando passa circular pela Internet. Ao analisarmos os comentários presentes no Facebook, observamos que tal convite soa como convocação a opinar sobre a capa, o menino de vestido, a família do menino, entre outros aspectos. Os sujeitos que tomam para si o convite da revista passam a expressar suas opiniões de modo contundente, disputando significados e acionando diferentes posicionamentos.

Caracterizamos tal investigação como uma pesquisa qualitativa que se orienta pela análise de práticas que se produzem na internet:

[...] os seres humanos são portadores de práticas com as quais fazem, são e compreendem. Como portadores de práticas, por meio da participação em práticas, os indivíduos "representam" seus corpos e suas mentes, seus desejos e afins, suas emoções e seus valores de determinadas maneiras. Assim, eles adquirem identidade e pertença, papeis e relações, compreensão e responsabilidades. (LANKSHEAR; LEANDER; KNOBEL, 2015, p. 202).

De modo a construir uma compreensão sobre como a prática de postar comentários no Facebook produz sentidos sobre o mundo social, selecionamos comentários para análise de posicionamentos (BARTON; LEE, 2015). Ao analisar tais comentários/postagens, alinhamonos também aos pressupostos da Análise do Discurso pelo viés da Linguística Antropológica, como mencionado na Introdução, que se ocupa analisar a linguagem em uso de forma situada em determinadas culturas e comunidades (WORTHAM; REYES, 2015). Quando esta análise parte de discursos que são produzidos em contextos digitais, postagens e comentários assumem um papel fundamental na produção de sentidos de um texto-base, seja ele um vídeo, uma imagem, um texto verbal (LANKSHEAR; LEANDER; KNOBEL, 2015; WORTHAM; REYES, 2015).

Na ocasião deste estudo, havia mais de 400 comentários. Não nos detivemos a uma exaustiva análise quantitativa das postagens (ainda que isso se faça necessário também). Elencamos algumas, que se mostravam em destaque no Facebook, no exercício reflexivo de analisar discursivamente tais comentários. Outras postagens poderiam ser selecionadas com o mesmo intuito, sem prejuízo a este estudo, de caráter exploratório ${ }^{6}$.

Selecionamos uma primeira postagem que ilustra o modo como se dão a construção de significados pelos participantes que acessam textos em redes sociais:

\footnotetext{
${ }^{6}$ Optamos por fazer prints das postagens que constam na página da revista Nova Escola no Facebook, a fim de que seja possível visualizar os comentários do modo como foram produzidos, conservando a data e horário em que foram postados, além das curtidas que o comentário recebeu. Tomamos o cuidado de retirar nomes e fotos das pessoas envolvidas.
} 


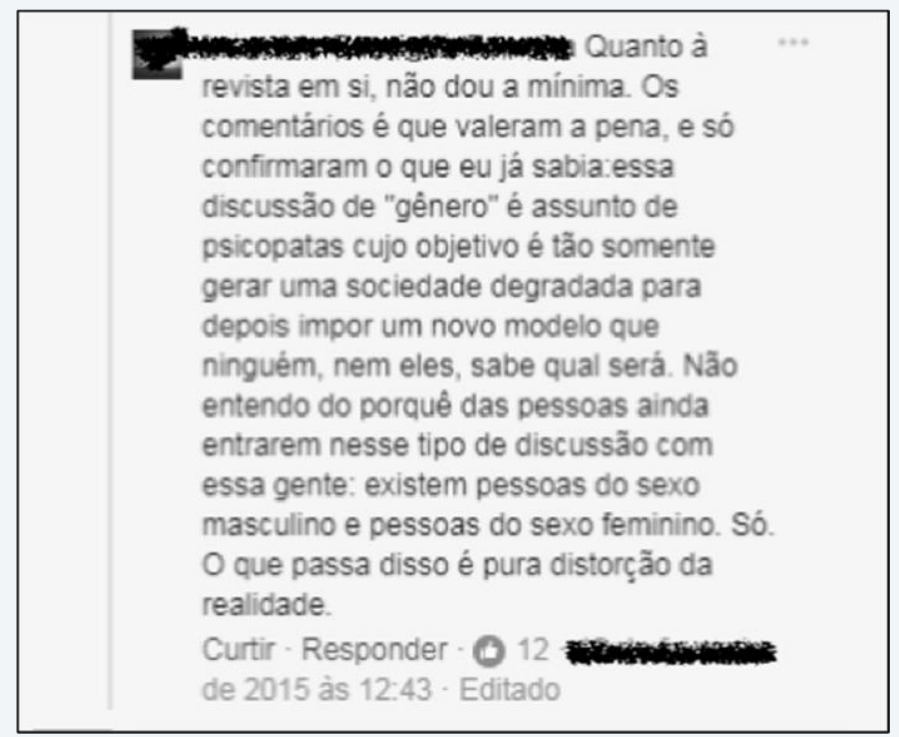

Figura 1: Print de Postagem no Facebook

$\mathrm{O}$ primeiro comentário selecionado traz à cena o posicionamento do enunciador quanto ao material disponibilizado: "quanto à revista em si, não dou a mínima. Os comentários é que valeram a pena, e só confirmaram o que eu já sabia: essa discussão de "gênero" é assunto de psicopatas [...]". O/a enunciador/a da postagem evoca uma prática de letramento que parece ser comum no universo das redes sociais: a construção de posicionamentos sobre um artefato cultural - no caso, o artigo de uma revista - sem acessá-lo, considerando exclusivamente a imagem de capa, enquanto recurso semiótico, e os comentários disponibilizados na mesma página. A sua crítica parte de um posicionamento epistêmico (BARTON; LEE, 2015) assumido antes da leitura, qual seja: "gênero é assunto de psicopatas cujo objetivo é tão somente gerar uma sociedade degradada". Mais adiante, conclui seu posicionamento: "existem pessoas do sexo masculino e do sexo feminino. Só. $O$ que passa disso é pura distorção da realidade”.

O posicionamento assumido neste enunciado não é algo que causa surpresa: trata-se de uma representação da heteronormatividade (LOURO, 2008; MISKOLCI, 2013) que classifica o mundo social numa ordem binária masculino $\mathrm{X}$ feminino, e qualquer mudança que destoe desta ordem passa a ser classificada como uma "psicopatia". Nesta lógica, parece estar implícita uma linearização entre identidade de gênero e sexualidade: homem masculino - heterossexual; mulher - feminina - heterossexual.

A prática de atribuição de sentido sem a devida leitura do texto referenciado pela imagem da capa é também alvo de problematização, como no comentário selecionado a seguir: 


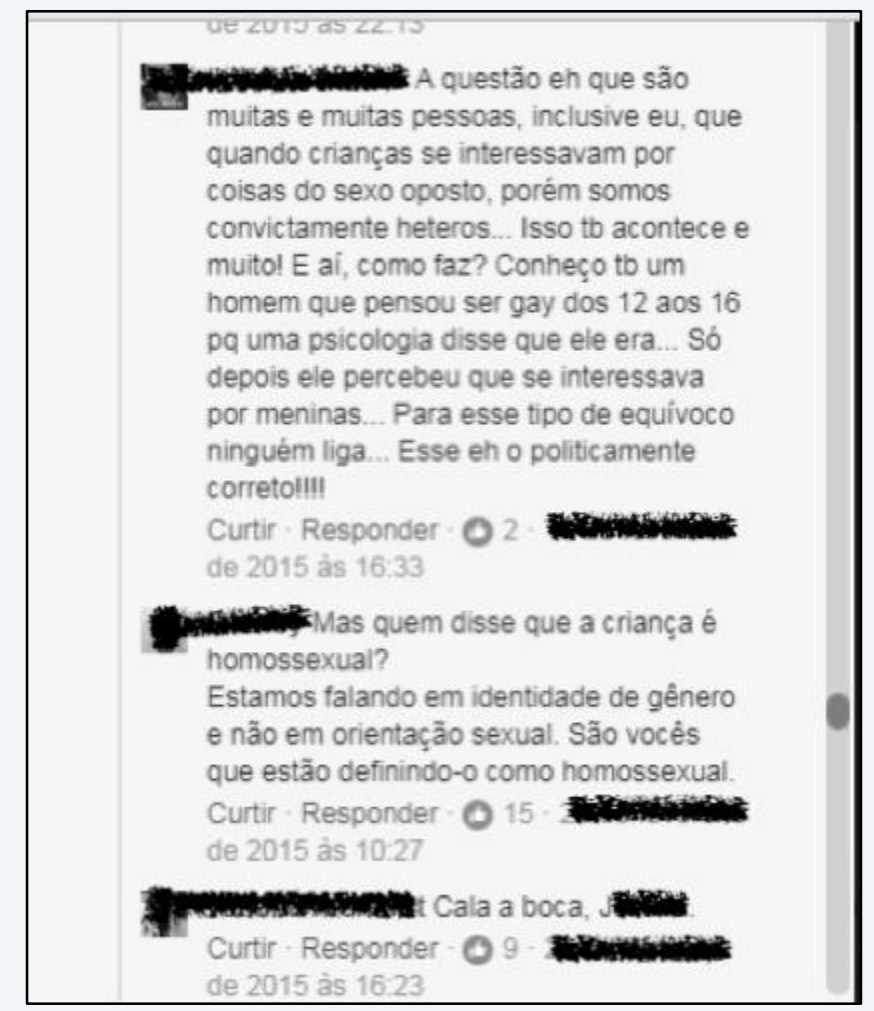

Figura 2: Print de Postagem no Facebook

O segundo comentário visto nesta imagem produz uma pergunta fundamental: "mas quem disse que a criança é homossexual'? Sua pergunta se coloca como um ato em resposta a toda uma série de críticas à capa, tal como na postagem logo anterior, a qual a enunciadora narra situações de equívocos entre performance de gênero e a determinação de uma (homo)sexualidade. Nesta, também verificamos um posicionamento epistêmico que se atém a uma heterossexualidade compulsória (MISKOLCI, 2012) que não é impedida de ser exercitada, ainda que não corresponda às práticas de gênero correspondente. Esse discurso é despreferido justamente pela postagem seguinte, quando a enunciadora evoca um posicionamento que problematiza a relação gênero e sexualidade.

Para nossas próximas análises, propomos examinar discursos ancorados em epistemes do campo das religiões e, menos frequente, das ciências, temas que emergiram em nossas primeiras leituras dos comentários no Facebook. Entendemos que estas epistemes desempenham um significativo papel para sustentar certa argumentação na produção de posicionamentos e jogos de verdade no debate produzido a partir da postagem da capa. 


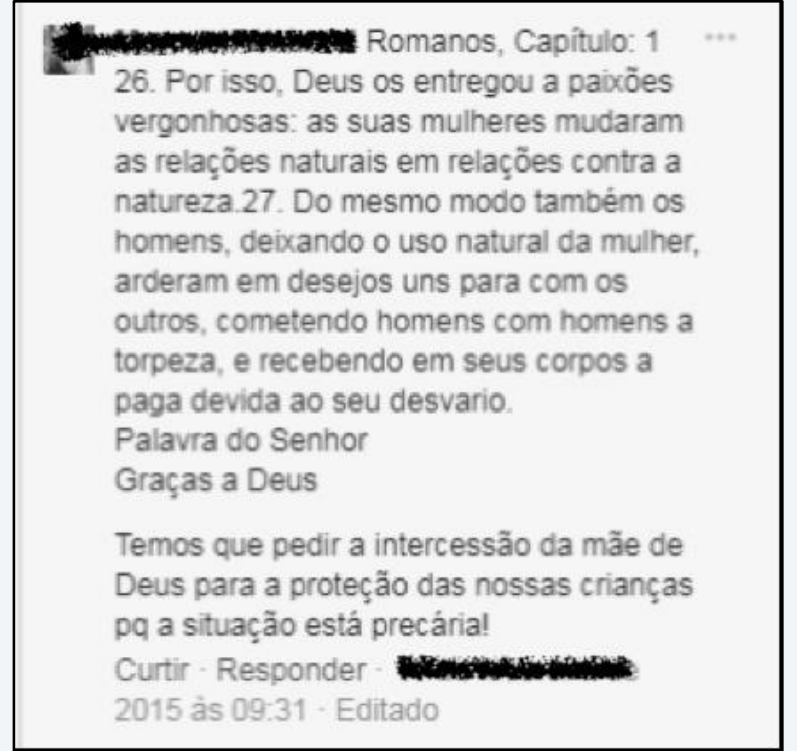

Figura 3: Print de Postagem no Facebook

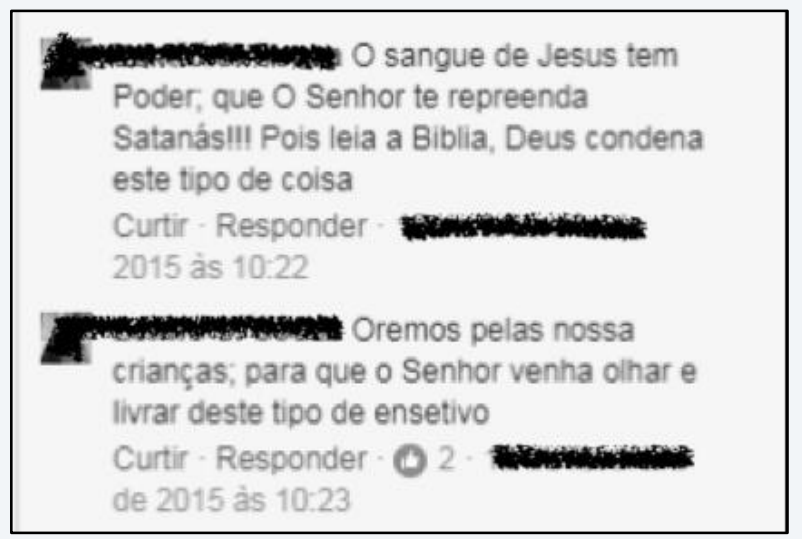

Figura 4: Print de Postagem no Facebook

Nestes comentários, o texto bíblico é acionado para expressar a inconformidade com a proposta da revista em discutir relações de gênero no contex to escolar. Sua inserção no debate suscitado pela postagem da capa com o menino Romeo evoca a contrariedade com o que seria o propósito divino: "Deus condena esse tipo de coisa". Não temos como objetivo realizar uma exegese bíblica, mas investir numa análise acerca das relações entre os discursos religiosos e a verdade. O uso da passagem bíblica parece ter caráter de argumento último, é a própria "palavra de Deus", a "palavra da salvação". Aquela que pode salvar as crianças do "satanás", da "situação precária" representada pela possibilidade de que meninos usem vestidos, mais que isso, que a ordem normativa dos gêneros seja subvertida, desafiada.

A vinculação com a verdade faz dos discursos religiosos uma potente estratégia para mobilizar os sujeitos em torno de certas compreensões das relações de gênero e sexualidades. A presença de enunciados que evocam posicionamentos afeitos à moral cristã no debate travado no Facebook não é algo incomum. Vem se tornando algo cada vez mais presente no 
debate público contemporâneo, especialmente na internet e nos meios de comunicação de massa. Interessa-nos pensar, portanto, na produtividade desses discursos, nos seus efeitos na condução das ações dos sujeitos.

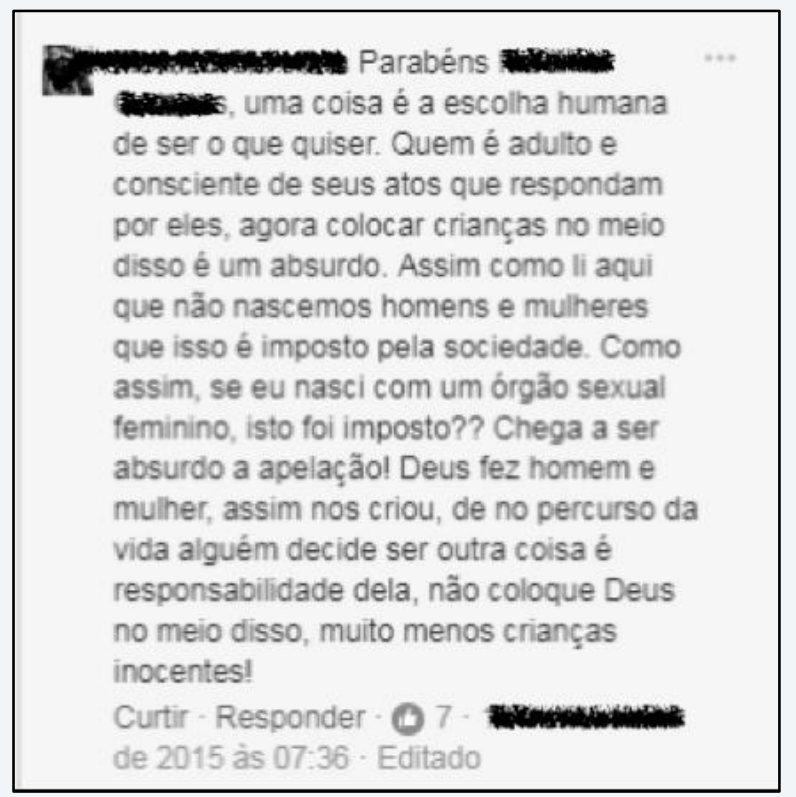

Figura 5: Print de Postagem no Facebook

Na figura acima, selecionamos o comentário "Deus fez homem e mulher, assim nos criou". O argumento generalizante evoca um posicionamento epistêmico pautado na evidência de um projeto divino que englobaria todas as pessoas, sem escapatória. Associamos a eficácia desse posicionamento à relação com a verdade e aos modos como os discursos religiosos vêm se colocando nas práticas sociais, sendo acolhidos e encontrando meios para funcionar como verdadeiros sob caráter impositivo e doutrinário (CASTRO; FERRARI, 2017).

Foucault (2008) problematiza o pertencimento doutrinário como algo que se constrói a partir do compartilhamento, por um grupo de indivíduos, de um mesmo conjunto de discursos, pelo reconhecimento das mesmas verdades e pela conformidade com os discursos validados. No comentário acima, a pessoa que escreve alinha-se a outra que já havia destacado a impossibilidade, no plano divino, de que existam homens/meninos que ousem romper a ordem considerada natural: a heteronormativa. Usar determinadas vestimentas e adornos seria próprio de alguns indivíduos e não de outros. Um menino de vestido fere, portanto, esse princípio básico. Não faz sentido na visão dessas pessoas o questionamento sobre a natureza dada por seu deus, ou seja, nascer homem ou mulher.

Parte da sociedade brasileira tem em sua base epistêmica uma rede discursiva de caráter religioso, mais especificamente cristão, que age decisivamente na construção de 
experiências religiosas, a partir das relações que os sujeitos estabelecem com preceitos morais, elaborando experiências de fé. Ao mesmo tempo, são subjetivados e conduzidos a certos modos de agir e viver. Com os efeitos dessa discursividade, passamos a nos ocuparmos de nós mesmos, dos nossos pensamentos, ações e sentimentos. Os posicionamentos construídos com esses discursos investem

[...] na crença em uma sexualidade como dimensão a ser vivida pelo casal heterossexual cisgênero e monogâmico, com fins reprodutivos, o que se coloca como modelo de um comportamento "normal e sadio". Homem e mulher figuram como entidades fixas, num esquema de gêneros binários e opostos, definidos por sua "natureza", ou seja, homem-pênis e mulhervagina. (CASTRO; FERRARI, 2017, p. 88).

\section{"[...] se eu nasci com um órgão sexual feminino, isso foi imposto??".}

posicionamento baseado em uma naturalidade constituída pelo divino dificulta a sua problematização e a evocação de outras epistemes. Em sua artificialidade, os gêneros são imputados a um corpo a partir da associação entre certa anatomia e as expectativas e normas construídas acerca do feminino e do masculino, investindo sobre o sujeito para que essa relação seja natural, contínua e concreta, como já mencionamos ao abordar a heteronormatividade e a heterossexualidade compulsória.

Quando se trata das crianças, tal associação parece se tornar mais forte, tendo em vista a ideia de que a infância se distancia de qualquer protagonismo e autonomia na definição de quem somos. Como podemos observar no comentário, a existência do menino Romeo e sua exposição na capa de uma revista, implicaria em um tipo de "influência" para modificar algo que está dado e sobre o qual "crianças inocentes" não seriam capazes de decidir. Porém, como podemos observar em outros comentários, não há consenso absoluto quando se trata desse debate.

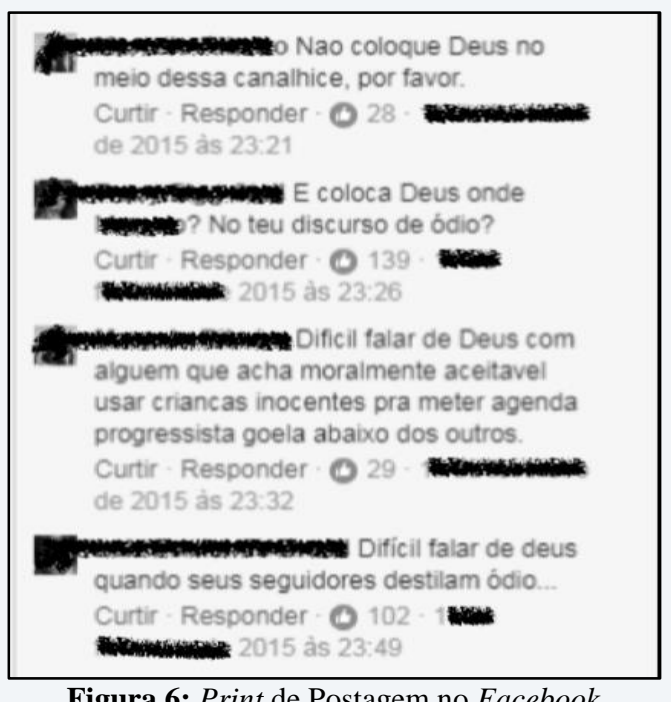

Figura 6: Print de Postagem no Facebook 


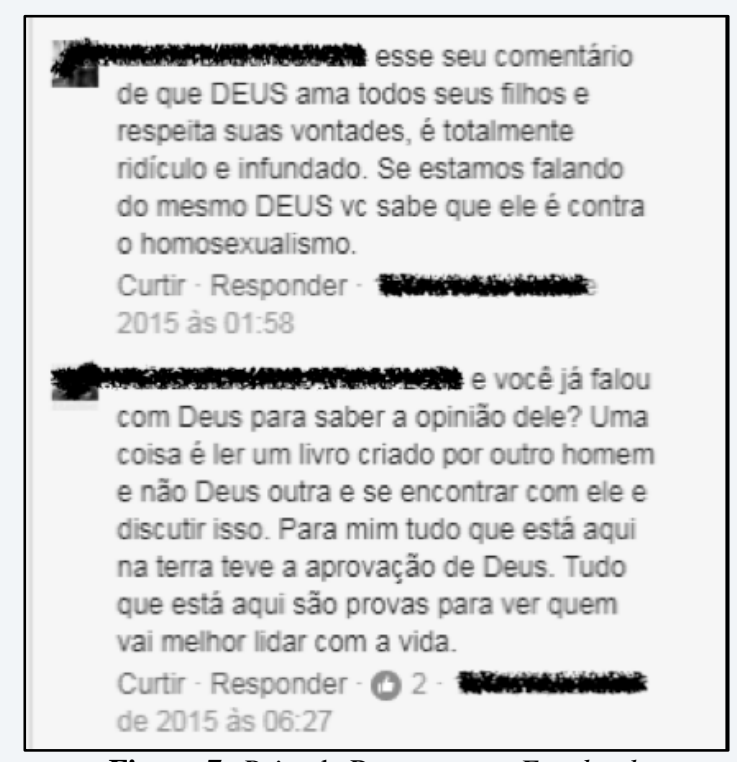

Figura 7: Print de Postagem no Facebook

Associar discursos de ódio com religiosidade ou com educação parece ser, no mínimo, incômodo. No caso dos comentários nas imagens acima, percebemos um debate acirrado em torno da significação sobre o uso de elementos discursivos religiosos para condenar a situação apresentada pela capa da revista Nova Escola. O discurso de ódio aparece para demarcar certo tipo de posicionamento epistêmico que, revestindo-se com proposições religiosas, condena a atitude da revista e também da família do menino Romeo ao não somente autorizá-lo a usar vestidos, mas apoiá-lo e acolhê-lo em suas vontades.

Há, deste modo, distintas relações com os discursos religiosos presentes nesses comentários, algo que rompe com o caráter generalizante e naturalista apregoado nos comentários anteriores. $\mathrm{O}$ mesmo deus que é utilizado para a condenação é também associado ao amor e ao respeito. Nosso argumento é que o funcionamento dos discursos religiosos, embora alocados no lugar da verdade, ao agir como direcionador de ações e pensamentos, pode tanto capturar os sujeitos em torno do seu caráter de verdade frequentemente inquestionável, superior, absoluto, quanto possibilitar estratégias de manutenção da heteronormatividade.

\section{Considerações finais}

Ao iniciarmos este texto, nos ancoramos em um duplo objetivo. O primeiro deles foi de construir uma compreensão sobre como letramentos constituem um potente espaço de produção de posicionamentos sobre o mundo social. Quanto a este, entendemos que a 
produção escrita, como mecanismo de engajamento dos participantes das redes sociais, é resultada de uma leitura superficial do artefato postado na rede. A prática de leitura reduz-se a elementos semióticos da imagem da capa da revista, e poucos indicaram efetivamente terem "clicado" no link para exercerem uma leitura de todo o material postado, no caso do contexto em análise.

Quando a leitura não é da capa, ela é dos comentários: parece que muitos participantes se engajam mais em longos exercícios de réplicas e tréplicas do que da leitura da revista. Há uma intensa disputa, marcada mais pela tentativa de persuasão (quando não, de ofensa) do que de que convergências. Ainda assim, a produção escrita acontece, e posicionamentos diversos são produzidos, cada vez mais distantes do objeto sob escrutínio - um artigo de uma revista.

Isto nos leva ao nosso segundo objetivo, que era analisar como a heteronormatividade era sustentada nestes comentários. Este conceito, contudo, não foi acionado a priori: ele partiu tanto pela nossa leitura prévia dos comentários críticos à revista, quanto da entrevista do editor, mencionado na Introdução. Nela, ficou marcado o quanto os chamados haters se mobilizaram para atacar a publicação.

Assim, na breve análise dos comentários selecionados, pudemos observar um posicionamento ancorado numa episteme de ordem religiosa e, menos frequente, científica. Textos bíblicos são constantemente evocados como elementos que orientam a avaliação dos comentários publicados e da capa da revista. Isso denuncia o quanto a religiosidade constitui o mecanismo de ordenação da vida social, sobretudo no campo da educação e da política em nosso país. Tal ordem é marcada por uma heteronormatividade que nega outras formas de construir a vida social.

Não nos propusemos a uma análise exaustiva dos comentários, por questões inclusive de espaço; contudo, apostamos numa possível "generalização naturalística”, a depender das práticas de letramento na rede social dos leitores e leitoras deste texto ${ }^{7}$. Em outros termos, compartilhamos a expectativa de facilmente encontrarmos nos comentários de redes sociais ocorrências de posicionamentos críticos com base em pressupostos religiosos ou conservadores, sobretudo no momento político vigente.

São postos, deste modo, dois desafios ao campo da educação: primeiro, dar conta de um trabalho ético e cidadão, pautado na temática de gênero e sexualidade, enquanto saberes já legitimados em documentos oficiais do Ministério da Educação, conforme já analisado por

\footnotetext{
${ }^{7}$ Menga Ludke e Marli André colocam nos seguintes termos este tipo de generalização: "é possível, por exemplo, que o leitor perceba a semelhança de muitos aspectos desse caso particular com outros casos ou situações por ele vivenciados" (1987, p.23)
} 
Alexandre Cadilhe (2015). Por mais que forças políticas busquem deslegitimar esse saber, ele é inegável, inclusive pela sua ordem emergente no cotidiano escolar. Afinal, quantos Romeos já frequentam as escolas brasileiras?

Segundo, temos o desafio de pensar os letramentos dos/as estudantes na escola, cada vez mais distanciados das práticas sociais cotidianas, tais como participar de uma interação no Facebook. Como engajamos nossos alunos e alunas a produzir comentários de forma crítica, ancorada em diferentes epistemes, e efetivamente produzida a partir da leitura de um texto que exceda a sua capa? Não seria esse um letramento necessário, para evitarmos discussões marcadas exclusivamente pela disputa e pela ofensa?

Assim, conforme apresentado na epígrafe deste artigo, na Introdução, entendemos que estamos diante da emergência de novos modos de aprender a usar a língua(gem), e argumentamos pela urgência de letramentos críticos no contexto escolar para uma formação cidadã menos desigual, em combate ao sexismo, ao machismo e à homofobia.

\section{REFERÊNCIAS}

BARTON, David; LEE, Carmen. Linguagem online: textos e práticas digitais. São Paulo: Parábola, 2015.

BUTLER, Judith. Problemas de gênero: feminismo e subversão da identidade. Rio de Janeiro: Civilização Brasileira, [1990]2013.

CADILHE, Alexandre. Letramentos, gênero e sexualidade na escola: reflexões para uma transversalidade curricular. GARCIA-REIS, A.; MAGALHAES, T. (org.). Letramentos e práticas de ensino. São Paulo: Pontes, 2016, p.167-181.

CASTRO, Roney; FERRARI, Anderson. A "ideologia de gênero" e os processos educativos nos discursos religiosos: efeitos de poder-saber-verdade. In FERRARI, A.; CASTRO, R. (org.). Diversidades sexuais e de gênero: desafios e potencialidades de um campo de pesquisa e conhecimento. São Paulo: Pontes, 2017, p.75-99.

FABRICIO, Branca. Transcontextos educacionais: gêneros e sexualidades em trajetórioas de socialização na escola. In SILVA, Daniel; FERREIRA, Dina, ALENCAR, Claudiana (org.). Nova pragmática: modos de fazer. São Paulo: Cortez, 2014, p.145-189.

LANKSHEAR, Colin; LEANDER, Kevin; KNOBEL, Michele. Pesquisa de práticas na internet. In SOMEKH, Bridget \& LEWIN, Cathy (org.). Teoria e método da pesquisa social. Petrópolis: Vozes, 2015.

LEMKE, Jay. Letramento metamidiático: transformando significados e mídias. Revista Trabalhos de Linguística Aplicada, n.49, v.2, p.455-579, 2010. 
LOURO, Guacira Lopes. Um corpo estranho: ensaios sobre sexualidade e teoria queer. Belo Horizonte: Autêntica, 2008.

LOURO, Guacira Lopes. Gênero, sexualidade e educação: uma perspectiva pósestruturalista.12 ed. Petrópolis: Vozes, 2011.

LUDKE, Menga; ANDRE, Marli. Pesquisa em educação: abordagens qualitativas. São Paulo: EPU, 1986.

MISKOLCI, Richard. Teoria Queer: um aprendizado pelas diferenças. Belo Horizonte: Autêntica, 2013.

MOITA LOPES, Luiz Paulo. O novo ethos dos letramentos digitais: modos de construir sentido, revolução das relações e performances identitárias fluidas. In SIGNORINI, Inês; FIAD, Raquel. (org.). Ensino de língua: das reformas, das inquietações e dos desafios. Belo Horizonte: UFMG, 2012, p.204-229.

NELSON, Cyntia. A teoria Queer em linguística aplicada: enigmas sobre "sair do armário" em salas de aula globalizadas. In MOITA LOPES, Luiz Paulo (org.). Por uma linguística aplicada indisciplinar. São Paulo: Parábola, 2006, p.215-232.

PAIVA, Vera Menezes. Facebook: um estrado atrator na internet. In ARAUJO, Julio; LEFFA, Vilson. (org.). Redes sociais e ensino de línguas: o que temos a aprender? São Paulo: Parábola, 2016, p.65-80.

RIBEIRO, Claudia; XAVIER, Constantina. Trajetórias teórico-metodológicas em 10 anos de produção do GT 23 da Associação Nacional de Pós-Graduação e Pesquisa em Educação ANPEd. In Revista Periodicus, v.1, n.2, p. 1-19, 2014.

ROJO, Roxane. Pedagogia dos multiletramentos: diversidade cultural e de linguagens na escola. In ROJO, R.; MOURA, E. (org.). Multiletramentos na escola. São Paulo: Parábola, 2012, p.11-32.

SABAT, Ruth. Pedagogia cultural, gênero e sexualidade. Estudos Feministas, n. 11, v.1, p.921, 2001.

WORTHAM, Stanton; REYES, Angela. Discourse analysis beyond the speech event. New Tork: Routledge, 2015.

\section{$\underline{\text { SOBRE OS AUTORES }}$}

\section{Alexandre José Cadilhe}

Doutor em Estudos da Linguagem pela Universidade Federal Fluminense (UFF); Professor Adjunto da Universidade Federal de Juiz de Fora (UFJF) - Brasil, atuando junto ao Programa de Pós-Graduação em Linguística; Coordenador do Grupo de Pesquisa Interação, Sociedade e Educação (CNPq/UFJF). E-mail: alexandre.cadilhe@ufjf.edu.br

(iD) http://orcid.org/0000-0002-4818-6428 


\section{Roney Polato de Castro}

Doutor em Educação pela Universidade Federal de Fora (UFJF) - Brasil; Professor adjunto da Universidade Federal de Juiz de Fora (UFJF) - Brasil, atuando junto ao Programa de PósGraduação em Educação; Coordenador do GESED - Grupo de Estudos e Pesquisa em Gênero, Sexualidade, Educação e Diversidade. E-mail: roneypolato@gmail.com

(iD) http://orcid.org/0000-0002-6385-9096 